\title{
LAND DEFORMATION MONITORING USING D-INSAR TECHNIQUE DURING LOMBOK EARTHQUAKE OBSERVED BY SENTINEL-1A/B
}

\author{
*Pakhrur Razi ${ }^{1}$, Josaphat Tetuko Sri Sumantyo ${ }^{2}$, Joko Widodo ${ }^{3}$, Yuta Izumi ${ }^{4}$ and Daniele Perissin ${ }^{5}$ \\ ${ }^{1}$ Math and Natural Science, Universitas Negeri Padang; ${ }^{2}$ Center for Environmental Remote Sensing, Chiba \\ University; ${ }^{3}$ Agency for the Assessment and Application of Technology (BPPT); ${ }^{4}$ Center for Northeast Asian \\ Studies, Tohoku University; ${ }^{5}$ Lyle School of Civil Engineering, Purdue University, West Lafayette \\ *Corresponding Author, Received: 16 March 2020, Revised: 27 April 2020, Accepted: 05 May 2020

\begin{abstract}
The significant ground deformation occurred at Lombok Island due to the large scale of series Earthquake in shallow depth from July to August 2018. Extract the information of ground deformation on the study area, Differential Interferometry Synthetic Aperture Radar (D-InSAR) technique was applied. The observation supported by SAR satellite data of Sentinel-1A/B (C-band) $5.5 \mathrm{GHz}$ provided by the European Space Agency (ESA). The satellite direction observation is from ascending and descending orbit with vertical transmit and vertical received (VV) polarization. The data acquisition is taken from July 2018 to August 2018 in three pairs before and after the earthquake hit the Lombok Island. Three zones have significant land deformation during the Lombok earthquake in 2018 namely zone A, zone B and zone C with $16 \mathrm{~cm}, 25.2 \mathrm{~cm}$, and $28 \mathrm{~cm}$ uplift in the line of sight (LOS), respectively. The value carried out by comparing the two-close time acquisition before and after the earthquake. Finally, the result of D-InSAR processing validates by ground data observation taken from an optical image of airborne.
\end{abstract}

Keywords: D-InSAR, Interferometry, Land Deformation, Lombok Earthquake, Synthetic Aperture Radar.

\section{INTRODUCTION}

The significant earthquake activity at Lombok Island is not recorded for a long time. However, suddenly the sequences of earthquakes shaking the island with high magnitude in shallow depth. It has destroyed buildings, killed hundreds of people, and injuring thousands of others. Also, triggering the landslide in many places. The earthquake was starting from the end of July 2018 and continuing until March 2020 with low intensity. There are five times a series of significant earthquakes with more than magnitude 6. On July 29, 2018, with M 6.4 in epicenter depth is about $14 \mathrm{~km}$, August 5, 2018, with M 7.0 in $15 \mathrm{~km}$ depth, August 9, 2018, with 6.2 in $15 \mathrm{~km}$ depth, and August 19, 2018, in the same day with M 6.3 and M 6.9 in $16 \mathrm{~km}$ and $21 \mathrm{~km}$ depth [1], respectively.

Measurement of the land deformation on the area due to the earthquake is useful to study the characteristics, its effect, and information for the reconstruction area. In observation, three pairs of Sentinel-1A/B SAR data were applied using Differential Interferometric Synthetic Aperture Radar (D-InSAR) Technique. The information observed from July 27, 2018, to August 20, 2018, provided by The European Space Agency (ESA).

These research aims are to monitor the land deformation using the D-InSAR technique and generate the land deformation information map that can be useful to the authorities in reconstructing, scientific information and developing the area.

\section{STUDY AREA AND SATELLITE DATASET}

The Lombok Island located between the subductions zone of Indo-Australia plate to the Sunda plate in Southern and the Flores thrust backarc in Northern. Also, in Western and Eastern between Lombok and Bali Island, and Lombok and Sumbawa Island exist the Bali fault and Sumbawa fault, respectively. In a subduction zone, IndoAustralia plate beneath to the Sunda plate while the Flores thrust fault is the reverse fault. Also, Lombok located an active volcano that part of a magmatic arc of the Sunda plate.

In observation, the Lombok earthquake, SAR data in both ascending and descending orbit of satellite Sentinel-1A/B collected. The data were taken before and after an earthquake shook up the Island provided by the European Space Agency (ESA). The center frequency of the satellite is 5.4 $\mathrm{GHz}$ with $5.54 \mathrm{~cm}$ wavelength in $\mathrm{VV}$ (vertical transmit and vertical receive).

The satellite dataset of Sentinel-1 A/B used to 
observe the land deformation during the Lombok earthquake listed Table I.

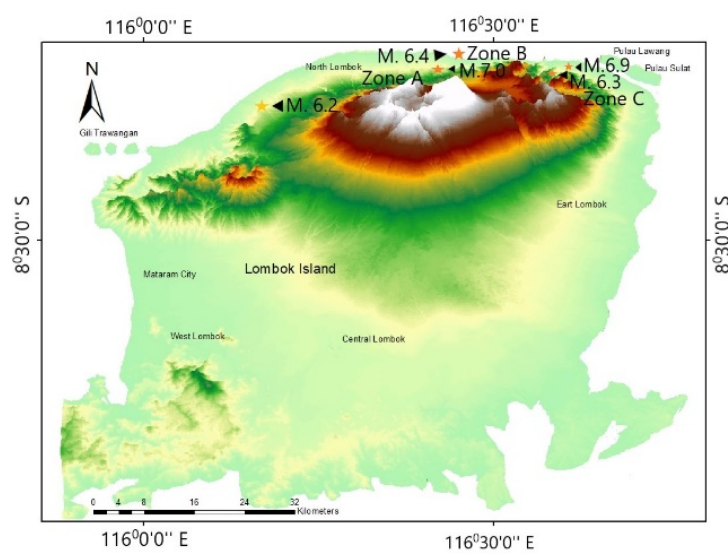

Fig. 1 Digital Surface Model (DSM) of Lombok Island provided by ALOS-JAXA

Fig.1 depicted the surface model of Lombok Island that extracted from PRISM (Panchromatic Stereo Mapping Sensor on ALOS (Array L-band Observation Satellite) that provided by JAXA (Japan Aerospace Exploration Agency). The data represent the land terrains with approximately 5 meters in spatial resolution [2]. The epicenter of the significant earthquake and significant land deformation area (Zone A, Zone B dan Zone C) inset into the model.

Tabel 1 Satellite data set of Sentinel-1A/B for observation Lombok earthquake.

\begin{tabular}{|l|l|l|l|l|l|l|}
\hline $\begin{array}{l}\mathrm{N} \\
\mathrm{o}\end{array}$ & Orbit & $\begin{array}{l}\text { Satell } \\
\text { ite }\end{array}$ & $\begin{array}{l}\text { Beam } \\
\text { swath } \\
\text { mode }\end{array}$ & $\begin{array}{l}\text { Acquisition } \\
\text { time }\end{array}$ & $\begin{array}{l}\text { Polari } \\
\text { zation }\end{array}$ & $\begin{array}{l}\text { Inc. } \\
\text { angle }\end{array}$ \\
\hline 1 & Ascending & $\begin{array}{l}\text { S1- } \\
\text { A/B }\end{array}$ & IW3 & $\begin{array}{l}27 / 07 / 2018- \\
02 / 08 / 2018\end{array}$ & VV & $43.76^{0}$ \\
\hline 2 & Descending & $\begin{array}{l}\text { S1- } \\
\text { A/B }\end{array}$ & IW2 & $\begin{array}{l}30 / 07 / 2018- \\
05 / 08 / 2018\end{array}$ & VV & $39.11^{0}$ \\
\hline 3 & Ascending & $\begin{array}{l}\text { S1- } \\
\text { A/B }\end{array}$ & IW3 & $\begin{array}{l}14 / 08 / 2018 \\
20 / 08 / 2018\end{array}$ & VV & $43.76^{0}$ \\
\hline
\end{tabular}

In first observation due to the M 6.4 on July 29, 2018, with about $14 \mathrm{~km}$ depth in zone B (Fig. 1). Combination of the satellite Sentinel $1 \mathrm{~A}$ and $1 \mathrm{~B}$ with acquisition time 27/07/2018 and 02/08/2018 in ascending orbit extracted, respectively. The beam swath is Interferometric Wide 3 (IW3) with a $3.5 \mathrm{x}$ 22.6 meters spatial resolution [3]. Furthermore, the second observation is using a combination of Sentinel 1A/B with acquisition time 30/07/201805/08/2018 in descending orbit. The incidence angle is low than the first observation with $3.1 \mathrm{x}$ 22.7 meters resolution [3]. In the second observation is to extract the information of land deformation a result of $\mathrm{M} 7.0$ in $15 \mathrm{~km}$ depth on August 5, 2018, at zone A (Fig. 1).

The next significant earthquake occurred on
August 19, 2018, at zone C (Fig. 1). On the same day twice earthquake with M 6.3 and M 6.9 in 16 $\mathrm{km}$ and $21 \mathrm{~km}$ depth, respectively. The epicenter for both earthquakes closed relatively. The observation during the earthquake, the combination SAR data of Sentinel 1A/B on 14/08/2018-20/08/2018 extracted.

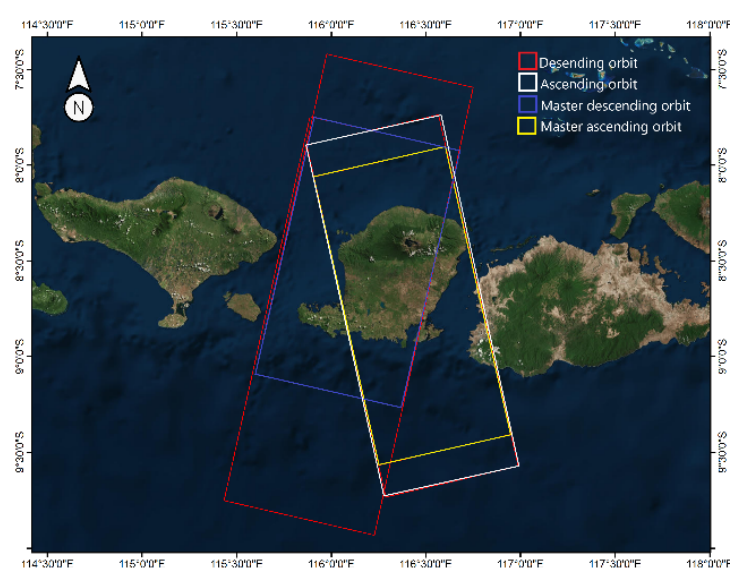

Fig. 2 The footprint of Sentinel-1A/B observe from both ascending and descending orbits.

Fig. 2 show the footprint of Sentinel-1A/B that projected to study area in Lombok Island. The square white line is area observation captured in ascending orbit while the square red line is descending orbit. The yellow and blue square are the master image belong to the ascending and descending orbits, respectively.

\section{METHODOLOGY}

Observation of the land deformation carried out by applying the Differential Interferometric Synthetic Aperture Radar (D-InSAR) technique. The technique has proven effective to detect the land deformation on the earth's surface [4-6]. In the changes detection on the Earth surface, two SAR images taken with the same position and orbit in different time acquisition require [6]. In SAR processing one image labeled as master image and another is the slave image.

To obtain the interferogram of land deformation carried out by a complex multiplication master image with a conjugate of slave images [7].

The interferometric phase difference between two SAR data is proportional to the slant range $R$ difference and divided by wavelength $\lambda$ [8].

$$
\begin{aligned}
& \phi_{1}=\frac{4 \pi R}{\lambda} \\
& \phi_{2}=\frac{4 \pi(R+\Delta R)}{\lambda} \\
& \Delta \phi=\phi_{2}-\phi_{1}=\frac{4 \pi \Delta R}{\lambda}
\end{aligned}
$$




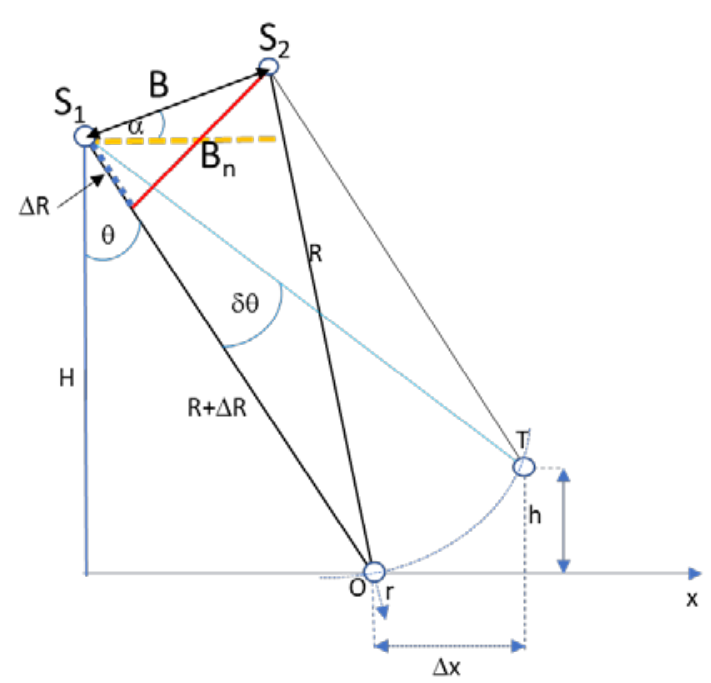

Fig. 3 The geometry of Interferometric SAR system

Fig. 3 presents the schematic geometry of the Interferometric Synthetic Aperture Radar system. $S_{1}$ and $S_{2}$ represent the satellite 1 and satellite 2 position on the space, respectively. Perpendicular distance for both satellites is marked by $B_{n}$ and distance satellite to target $T$ on the Earth surface in slant range represents with $R$. The satellite elevation and look angle symbolize with $H$ and $\theta$, respectively.

There is five-component that contribute to the interferometric phase in the D-InSAR technique [9], [10].

$$
\begin{gathered}
\Delta \varphi_{m, s}(T)=\Delta \varphi_{m, s}^{\text {flat }}(T)+\Delta \varphi_{m, s}^{T o p o}(T)+ \\
\Delta \varphi_{m, s}^{\operatorname{disp}}(T)+\Delta \varphi_{m, s}^{\text {atm }}(T)+\Delta \varphi_{m, s}^{\text {nois }}(T)
\end{gathered}
$$

In D-InSAR processing, some component is estimated, filtered and removed then only displacement component $\Delta \varphi_{m, s}^{\text {disp }}$ is remaining.

The amount and pattern of land deformation are calculated based on the Interferogram phase between two different time acquisitions. The interferogram phase presented by a range of color in the spectrum from blue to red. The rapid pattern of the phase represents the half wavelength of the carrier signal SAR satellite.

The interferometric phase is ambiguity in $\mathbf{2} \boldsymbol{\pi}$, to obtain the real value it should be unwrapped.

Fig 4. Portray the flow of D-InSAR processing technique to obtain the land deformation value during the Lombok Earthquake. From the Sentinel$1 \mathrm{~A} / \mathrm{B}$ satellite data, each pair of the image is coregistered to ensure each ground target has equal range and azimuth in both master and slave images. After each pair co-registration, the images are filtered and multi-looked to obtain the interferogram phase. Furthermore, a un-wrapped-

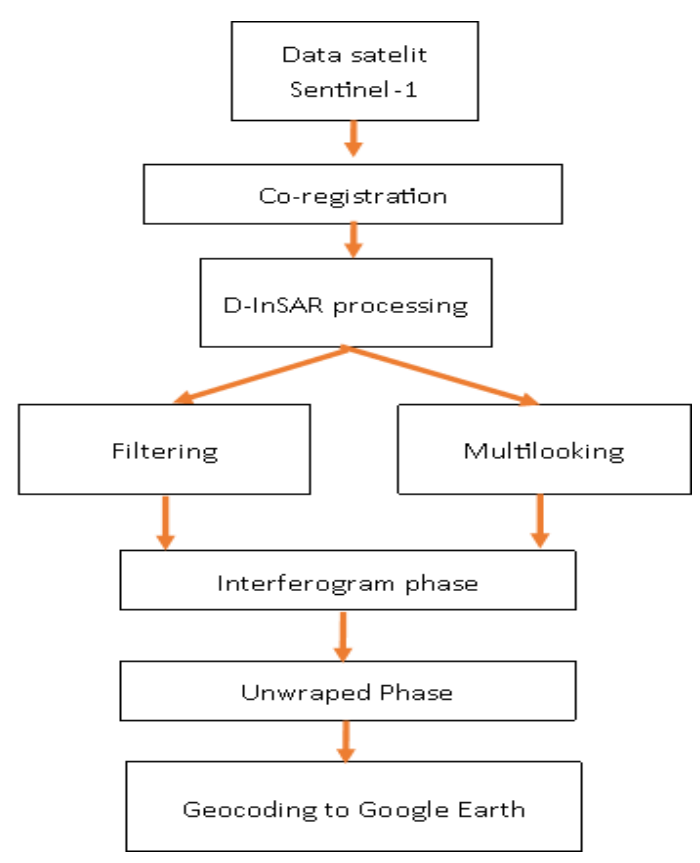

Fig. 4 The D-InSAR processing chain of the Lombok earthquake.

phase is required to produce the real value of land deformation. Finally, the result geocodes into an optical layer of google Earth.

\section{RESULT AND DISCUSSION}

There are three periods of the earthquake that has a significant impact on land deformation in Lombok Island. The earthquake occurred on July 29, 2018, followed by August 5, 2018, and August 19, 2018. The earthquake is the result of Flores backarc thrust in Northern of Lombok Island. The first period with M 6.4 at epicenter $8.2^{0} \mathrm{~S}$ and $116.508^{0}$ $\mathrm{E}$ in $14 \mathrm{~km}$ shallow depth. Based on the fringes of the interferometric phase on the area observed by Sentinel-1A/B with ascending orbit and processed using the D-InSAR technique leads to the deformation approximately $16.8 \mathrm{~cm}$ uplift. Whereas each fringe associated with $2.8 \mathrm{~cm}$ of half wavelength of the carrier signal (Fig.5). The second term of the earthquake with $\mathrm{M} 6.9$ at epicenter $8.319^{\circ} \mathrm{S}$ and $116.627^{\circ} \mathrm{E}$ in $21 \mathrm{~km}$ depth. The land deformation due to this earthquake is equal to 25.2 cm uplift (Fig. 6). The data observed by Sentinel $1 \mathrm{~A} / \mathrm{B}$ with descending orbit. The last earthquake is on August 19, 2018, whereas a twice-significant earthquake occurs on the day. The first is at 04:10:22 (UTC) with M 6.3 and $16 \mathrm{~km}$ depth followed by M 6.9 at 14:56:27 (UTC) with $21 \mathrm{~km}$ depth. For both times earthquake lead to the deformation, approximately $28 \mathrm{~cm}$ uplift in LOS that was observed by Sentinel $1 \mathrm{~A} / \mathrm{B}$ in ascending orbit (Fig. 7).

The thirds interferometric phase of the 
earthquake event is depicted in Figure 5, Figure 6 and Figure 7.

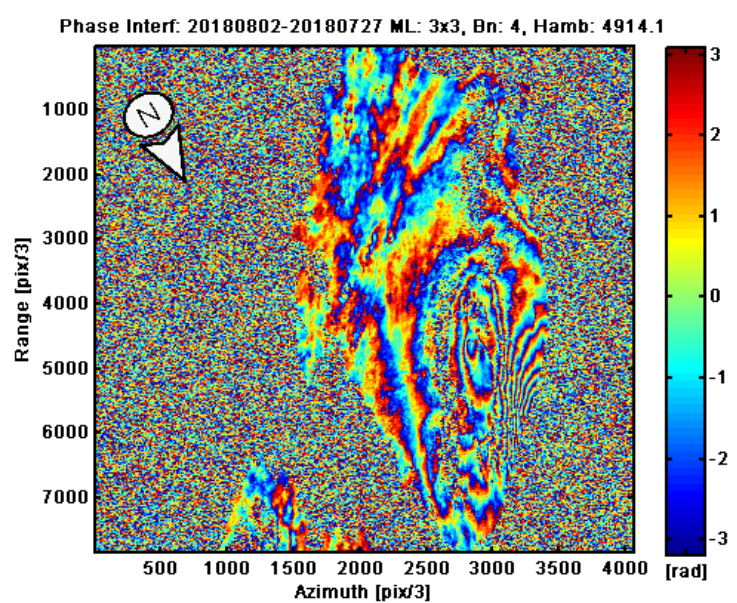

Fig. 5 The interferometric phase of the significant earthquake occurrence on July 29, 2018.

In Fig. 5 the radar flight (azimuth direction) is ascending orbit then radar signal that transmitted directly to the west part of Lombok Island. In North of Lombok apparent significant fringe changing with starting in the center of $8^{\circ} 13^{\prime} 14.36$ "S and $116^{\circ} 27^{\prime} 33.87^{\prime \prime E}$. Meanwhile, the epicenter of the earthquake is located in $8^{\circ} 17^{\prime} 13^{\prime \prime} \mathrm{S} 116^{\circ} 27^{\prime} 07^{\prime \prime} \mathrm{E}$.

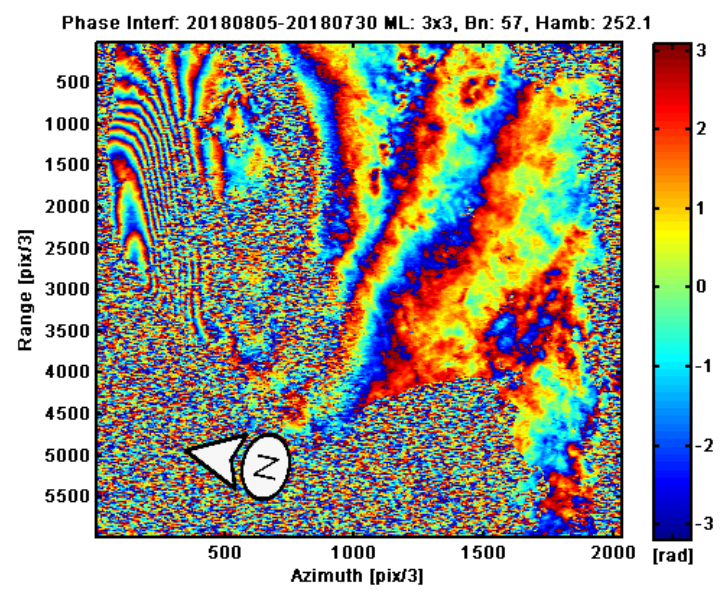

Fig. 6 The interferometric phase of the significant earthquake occurrence on August 5, 2018.

Fig. 6 presents deformation in the second time of significant earthquake observe by descending satellite orbit. In the North of Lombok island, significant deformation occurs with marked by changing of fringes.

Fig. 7 similar to the two figures above (Fig. 5 and Fig. 6), in third times significant earthquakes also occurred in North of Lombok Island, but the center of the fringe is moving from the west of North to East of North Lombok Island. The moving center of fringe associated with changing the epicenter of the Earthquake.

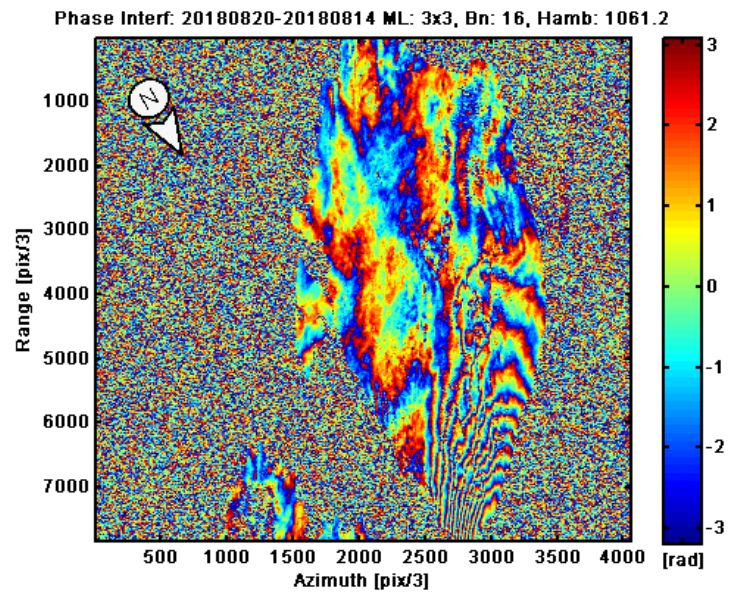

Fig. 7 The interferometric phase of the significant earthquake occurrence on August 19, 2018.

The interferometric phase is wrap form [11]. Unwrapped is required to obtain the real displacement value of land deformation for the three-period earthquake. Fig. 8 presented the unwrapped value of the interferometric phase. Unwrapped is a process to convert the interferometric phase in $\mathbf{2} \boldsymbol{\pi}$ to real value after interferogram flattening [12]. The unwrapped phase of interferometry for the third times significant earthquake presented in Fig. 8, Fig. 9, and Fig. 10, respectively.

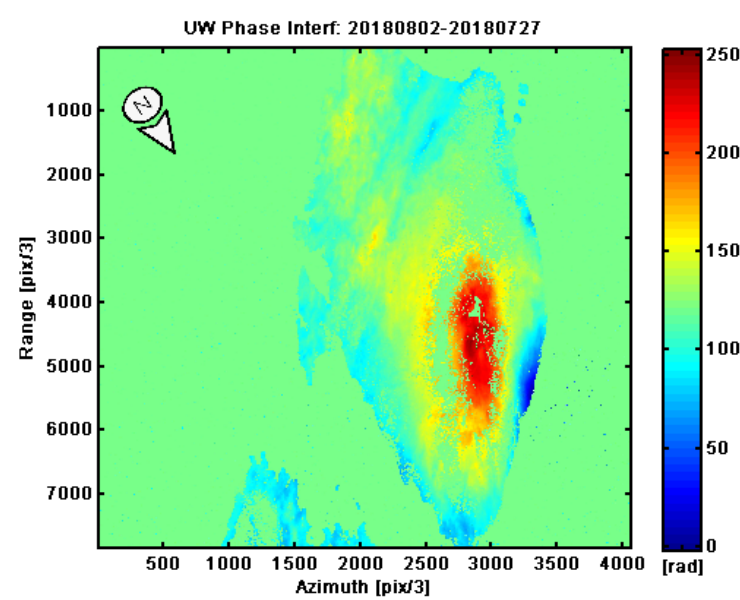

Fig. 8 Unwrapped phase interferometric of the significant earthquake occurrence in Lombok Island on July 29, 2018.

Fig. 8 depicted the value of land deformation in Lombok Island for the first earthquake event. The blue color indicates a significant area of $16.8 \mathrm{~cm}$ uplift in most coastal areas. However, in Northern of Lombok Island with close to the earthquake epicenter (dark blue) reach to $25 \mathrm{~cm}$ uplift. The area in red and yellow color also uplift with a range of 0 $8 \mathrm{~cm}$ and 8-13 cm, respectively.

Fig. 9 illustrate the land deformation area based on the second significant earthquake in Lombok Island on August 5, 2018. 


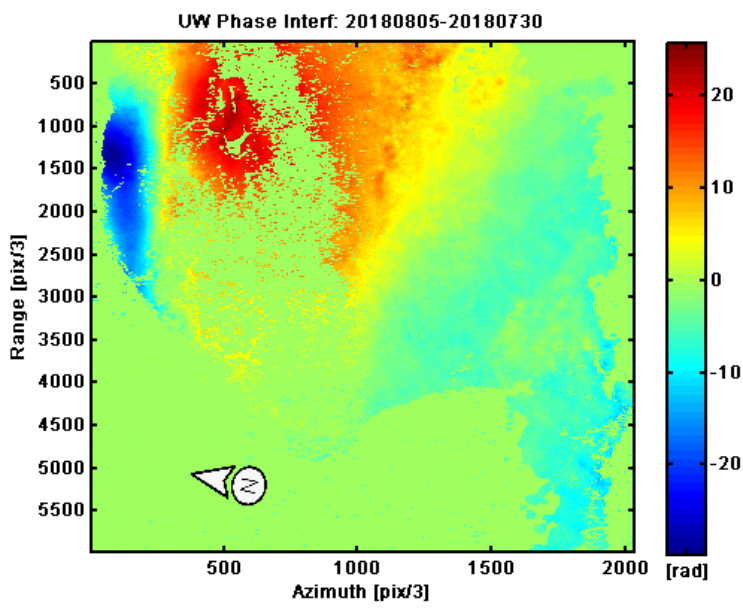

Fig. 9 Unwrapped phase interferometric of the significant earthquake occurrence on Lombok Island on August 5, 2018

The dark blue color indicates the highest land deformation with approximately $25.2 \mathrm{~cm}$ uplift located in Northern of Lombok Island close to the first earthquake (Fig. 8). The most of South of Lombok is a light blue that designates the area to uplift about 2-8 cm. Also, in the center of Lombok Island around Mt. Rinjani is 8-13.5 cm uplift.

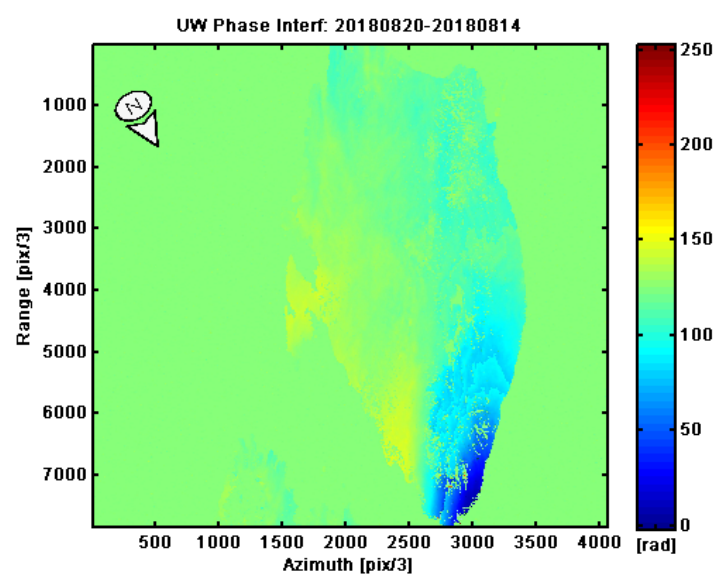

Fig. 10 Unwrapped phase interferometric of the significant earthquake occurrence on Lombok Island on August 19, 2018.

Fig. 10 shown the land deformation area for the third significant earthquake on August 19, 2018, In Lombok Island. Similar explanation with two Figures above (Fig. 8 and Fig. 9). The maximum value of land deformation due to the third earthquake is $28 \mathrm{~cm}$ uplift. However, the location is moved about $17.5 \mathrm{~km}$ to the East side of Northern of Lombok Island.

Based on the optical airborne image identify the damage of building in the North of Lombok island.

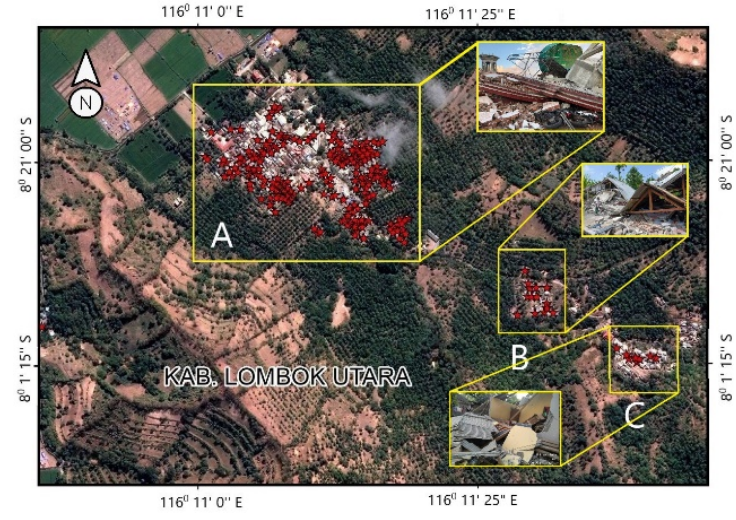

Fig. 11 Ground survey data observation using airborne [13] in North of Lombok Island

Fig. 11 shows the result of the airborne photoshoot in the North of Lombok Island. The most of building in square line (A) $8^{\circ} 21^{\prime} 0.53^{\prime \prime S}$ and $116^{\circ} 11^{\prime} 19.01^{\prime \prime E}$, (B) $8^{\circ} 21^{\prime} 10.12^{\prime \prime S}$ and 116 $11^{\circ}$ $34.27^{\prime \prime} \mathrm{E}, 8^{\circ} 21^{\prime} 14.50^{\prime \prime S}$ and $116^{\circ} 11^{\prime} 40.77^{\prime \prime} \mathrm{E}$ is collapse. This area is located between two epicenters of the earthquake that occurs on August 5, 2018, with M. 7.0 and M 6.2 on August 9, 2018, in $15 \mathrm{~km}$ depth.

Based on the unwrapped value, the land deformation on the Northern of Lombok Island calculated. For each period of earthquake impact to the deformation, $25 \mathrm{~cm}$ uplift in a different location. However, all events located on the Flores backarc thrust line. The fact ensures that the backarc thrust of Flores causes the earthquake. Based on the ground survey data, the area on the Northern of Lombok Island has significant damage to others.

\section{CONCLUSION}

The D-InSAR technique was successfully detected the land deformation during the earthquake event on Lombok Island. The observation of land deformation is using three pairs of Sentinel-1A/B data provided by ESA. The significant earthquake from the end of July until August 2018 leads to the land deformation on the Northern of Lombok Island. The deformation caused by M.6.4 mainshock in July 2018 leads to uplift approximately $16 \mathrm{~cm}$ in the line of sight (LOS) for Zone A. The second significant earthquake event caused by the M.7.0, on August 5, 2018, $25.2 \mathrm{~cm}$ Zone B uplift in LOS. However, some area in South of Mt. Rinjani is subsidence with a maximum of $20 \mathrm{~cm}$. The last significant event on August 19, 2018, leads to a 28 $\mathrm{cm}$ area in Zone $\mathrm{C}$ uplift in the line of sight (LOS). The result was correlated with the level of damage area base on the airborne observation. The area that closes to the epicenter of the earthquake has a significant number of building collapse than others. The level of vulnerability shocks in this area also influenced by soil structure composed of tuff stone, lava, and lava breccias. 
The landslide also confirmed in some locations particular in peak and North-East of Mt. Rinjani, it seems in the interferometric phase in the second earthquake event that triggered by M. 7.0 in $15 \mathrm{~km}$ depth. Also, the result of this research shows that based on the fringe in the interferometric phase on the third earthquake event, it seems the main fault of Lombok Island that spread from South to North. However, the fault line is not straight as published on the geological map [14] but is slightly curved eastward in the northern part of the MT. Rinjani. Furthermore, for local fault in Eastern of Lombok that spread from east to the center of Lombok also detected based on the interferometric phase on the third earthquake.

Then it can be concluded that 1). D-InSAR technique can be an alternative technique for mapping land deformation in a wide area at a low cost. 2). D-InSAR technique has a high accuracy of result measurement until the millimeter unit. 3). The interferometric phase of radar SAR can be used to detect the fault and landslide location accurately. 4). The level of infrastructure damage is associated with the level of land deformation.

\section{ACKNOWLEDGEMENTS}

The authors would like to European Space Agency (ESA), Universitas Negeri Padang, Japan Aerospace Exploration Agency (JAXA Japan), National Aeronautics and Space Administration (NASA) U.S, Indonesian National Board for Disaster Management (BNPB), and Indonesian Meteorological, Climatological, and Geophysical Agency (BMKG).

\section{REFERENCES}

[1] USGS, Earthquakes event in Lombok, 2018. [Online].

Available: https://earthquake.usgs.gov/earthquakes/even tpage/us2000ggbs/executive.

[2] JAXA, ALOS Global Digital Surface Model (DSM), Ver 2.1., EORC, JAXA, 2018, pp. 112.

[3] ESA, Interferometric wide swath, ESA 2000 2019. [Online]. Available: https://sentinel.esa.int/web/sentinel/userguides/sentinel-1-sar/acquisitionmodes/interferometric-wide-swath.

[4] Ferretti A, Satellite InSAR Data: Reservoir Monitoring from Space. Netherlands: EAGE, 2014, pp. 1-370.

[5] Hanssen R.F, Radar Interferometry - Data Interpretation and Error Analysis. New York:
Kluwer Academic Publishers, 2002, pp.1-327.

[6] Razi P, Sumantyo J. T. S., Perissin D, Febriany F, and Izumi Y., Multi-Temporal Land deformation monitoring in $\mathrm{V}$ shape area using Quasi-Persistent Scatterer (Q-PS) Interferometry Technique, in 2018-Progress in Electromagnetics Research Symposium, 2018, pp. 910-915.

[7] Razi P., Sumantyo J. T. S., Perissin D., and Kuze H., Long-Term Land Deformation Monitoring Using Quasi-Persistent Scatterer (Q-PS) Technique Observed by Sentinel-1A: Case Study Kelok Sembilan, Adv. Remote Sens., vol. 07, No. 04, 2018, pp. 277-289.

[8] Perissin D., Interferometric SAR Multitemporal Processing: Techniques and Applications, in Multitemporal Remote Sensing, Remote Sensing, and Digital Image Processing, No. 20, Springer, Cham, 2016, pp. 145-176.

[9] Razi P., Sumantyo J. T. S., Perissin D., Kuze H., Chua M. Y., and Panggabean G. F., 3D land mapping and land deformation monitoring using persistent scatterer interferometry (PSI) ALOS PALSAR: Validated by Geodetic GPS and UAV, IEEE Access, vol. 6, 2018, pp. 12395-12404.

[10] Izumi Y., Widodo J., Kausarian H., Demirci S., Takahashi A., Razi P., Nasucha M., Yang H., and Tetuko J.S.S., Potential of soil moisture retrieval for tropical peatlands in Indonesia using ALOS-2 L-band full-polarimetric SAR data, Int. J. Remote Sens., vol. 40, no. 15, Aug. 2019, pp. 5938-5956.

[11] Pepe A., A Review of Interferometric Synthetic Aperture RADAR ( InSAR ) MultiTrack Approaches for the Retrieval of Earth's Surface Displacements, Appl. Sci., 2017, pp. 1-39.

[12] Razi P., Sumantyo J. T. S., Febriany F., Nasucha M., and Aminuddin J., Interferometry Synthetic Aperture Radar (InSAR) Application for Flood Area Detection Observed by Sentinel-1A, in 2018 Progress in Electromagnetics Research Symposium, 2018, pp. 905-909.

[13] LAPAN, Gempa Lombok utara, http://pusfatja.lapan.go.id, 2018.

[14] ESDM, Peta Geologi Teknik Pulau Lombok, Jakarta: ESDM, 2014, pp. 1-8.

Copyright (C Int. J. of GEOMATE. All rights reserved, including the making of copies unless permission is obtained from the copyright proprietors. 